\title{
An anatomical variant: evaluation of accessory canals of the canalis sinuosus using cone beam computed tomography
}

\author{
K. Orhan ${ }^{1}$, C. Gorurgoz', M. Akyol ${ }^{2}$, S. Ozarslanturk ${ }^{3}$, H. Avsever ${ }^{3}$ \\ ${ }^{1}$ Department of Dentomaxillofacial Radiology, Ankara University, Ankara, Turkey \\ ${ }^{2}$ Department of Biostatistics, Yildirim Beyazit University, Ankara, Turkey \\ ${ }^{3}$ Department of Dentomaxillofacial Radiology, Faculty of Gulhane Dentistry, Health Sciences University, Ankara, Turkey
}

[Received: 27 October 2017; Accepted: 14 December 2017]

\begin{abstract}
Background: The anatomical variation of the anterior superior alveolar nerve described as canalis sinuosus (CS) is a less known structure of anterior maxilla. Due to the fact that it contains anterior superior alveolar nerve as well as veins and arteries, exact localisation of this structure will allow surgeons to avoid complications. Hence, the aim of this study was to verify the presence, reveal the frequency and characteristics of accessory canals of CS.

Materials and methods: This study was based on retrospective evaluation of cone beam computed tomography (CBCT) scans. A total of 1460 CBCT images were analysed and collected data were noted. The following parameters were recorded: age, sex, presence or absence of CS, location in relation to the adjacent teeth and impaction of canine teeth.

Results: A total of 6668 accessory canals were found in 1460 CBCT images. Of these, 672 (46.0\%) were from female patients, and 788 (54.0\%) were from male patients. 1034 (70.8\%) of 1460 images had at least one accessory canal of CS. Maxillary intercentral region is the area where accessory canals were seen most frequently ( $n=653,44.72 \%)$.

Conclusions: Canalis sinuosus is a bony canal which is incidentally found and less known structure of anterior portion of maxilla. Knowing the accessory canals deriving from this structure will allow surgeons to avoid complications and non-integration after dental implant procedures. Conventional imaging modalities have limited value in detecting this neurovascular structures. Therefore CBCT may have an important role for accurate diagnosis to reveal anatomical variations. (Folia Morphol 2018; 77, 3: 551-557)
\end{abstract}

Key words: canalis sinuosus, anatomical variation, cone beam computed tomography

\section{INTRODUCTION}

The dental implant placements as well as several surgical procedures such as orthognathic surgery, supernumerary or impacted teeth removal operations, cyst or tumour operations, endodontic and periodontal surgery are frequently performed in the anterior maxilla $[8,16]$. Nasal fossa, nasopalatine canal and incisive foramen are not the only structures that should be considered, but also some important neurovascular structures. The infraorbital nerve which

Address for correspondence: Prof. Dr. K. Orhan, Ankara University Faculty of Dentistry, Department of Dentomaxillofacial Radiology, Ankara, Turkey, tel:+903122965628, fax:+903122123954, e-mail: call53@yahoo.com 
is known as a branch of the maxillary nerve mainly provides innervation of this region. This nerve runs along infraorbital canal and is divided into three alveolar proximal branches: anterior, middle and posterior superior alveolar nerves. The anterior superior alveolar nerve is relatively thicker than the middle and posterior superior branches. This nerve innervates the incisor and canines and traverses maxillary anterior wall by a bony canal called canalis sinuosus (CS) $[2,15]$. This bony canal, where the anterior superior alveolar nerve passes through, contains arteries and veins $[11,13]$. Surprisingly, such an important canal is not known by practitioners unless encountering complications such as unexpected bleedings or paraesthesia. It is difficult to identify in routine conventional radiographs. In addition, many anatomy textbooks lack of detailed description of these its variations. Sometimes it can be misdiagnosed as an infectious periapical disease by professionals.

The conventional imaging modalities such as periapical and panoramic radiography are commonly used in dental practice by practitioners as precious diagnostic tools. Although they provides valuable information about dentomaxillofacial region, due to having some limitations (superimpositions, magnifications, distortions, low image quality), they often fail to obtain sufficient information. With the development of three-dimensional (3D) imaging modalities, cone beam computed tomography (CBCT) has gained widespread acceptance in dentistry. It provides high resolution, cross-sectional view and diagnostic reliability at lower costs and radiation doses $[1,12,18]$. It allows detailed multiplanar evaluation of maxillofacial region to be conducted for further analysis of the anatomical structures which could not have been detected by conventional imaging modalities $[4,6,10]$.

Due to only a few publications on anatomical variants of canalis sinosus available in literature and the fact that these variations commonly seen in CBCT evaluation as an incidental finding, practitioners do not know much about this anatomical variation. Not only increasing the knowledge of normal anatomical structures or variations but also preoperative identification of the course of nerves and vessels by radiographic evaluation has an important role, essential for safe surgical procedures. Hence, detailed multiplanar evaluation by using CBCT will provide accurate information of anatomical structures and their variations to prevent the damage of neurovascular structures. This study aims to assess the anterior maxillary region, presence of accessory canals (ACs) of
CS, describing their frequency, location, direction, and diameter in $\mathrm{CBCT}$ scans according to gender and age.

\section{MATERIALS AND METHODS}

This study was based on retrospective evaluation of CBCT scans. All CBCT scans were obtained from the patients referred for several reasons to the Department of Dentomaxillofacial Radiology, Health Sciences University and Ankara University, Turkey. This retrospective study was approved by the Local Research Ethics Committee (protocol 2012-KAEK-15/1508). CBCT scans used in the study were acquired on a 3D Accuitomo 170 (3D Accuitomo; J Morita Mfg. Corp., Kyoto, Japan) and Planmeca ProMax CBCT, Helsinki, Finland). All $C B C T$ images were examined independently by 2 dentomaxillofacial radiologists, each with at least 10 years' experience. All patients were informed about the investigation and gave their informed consent prior to the examinations according to the principles of the Helsinki Declaration, including all amendments and revisions. Demographic and all collected data were noted and only accessible to the investigators. Moreover, all examiners in the study only examined the images and were blinded to any other patient data in the radiographic examination procedure.

The study sample consisted of 1460 patients. CBCT images which have good diagnostic quality and sufficient imaging area were included to the study. The patients with trauma, congenital disorders, anamnesis of surgical procedures, and pathological disorders of the anterior maxilla were excluded from the study. The patients were divided into groups based on decades and gender. Any bony canal with approximately $1 \mathrm{~mm}$ diameter except for nasopalatine canal was evaluated using coronal, sagittal and axial $C B C T$ sections of $1 \mathrm{~mm}$ thickness. Moreover, the presence of canals was also classified according to regions, nearest adjacent teeth and also impacted teeth (Figs. 1-4). The interobserver reliability of detection of CS was determined in a consensus session. The final radiographic condition of each CS was obtained during a consensus meeting between the two professionals. In case of any disagreement, a third observer was also included in discussions in order to establish final classification.

For $\mathrm{CBCT}$ evaluations, proprietary manufacturer software (i-Dixel 2.0/One Data Viewer/One Volume Viewer; J Morita Mfg. Corp.) and Romexis software v. 3.7 (Planmeca Oy, Helsinki, Finland) were used. Images were viewed in a dimly lit room on a 30 inch Dell ${ }^{\mathrm{TM}}$ 3008WFP Flat Panel Monitor (Dell Inc., Round 


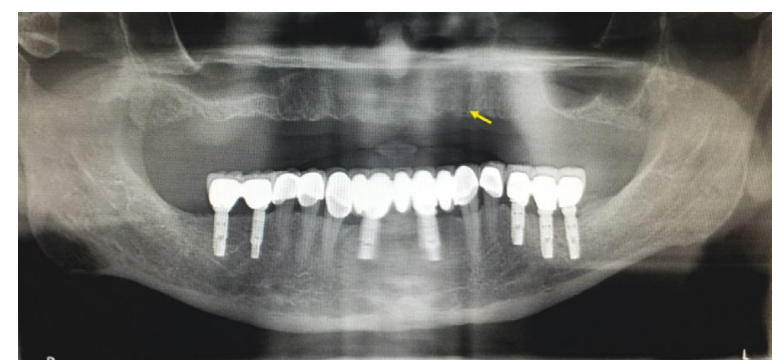

Figure 1. A panoramic radiograph with a suspected radiolucent line in the region of left canine (arrow).

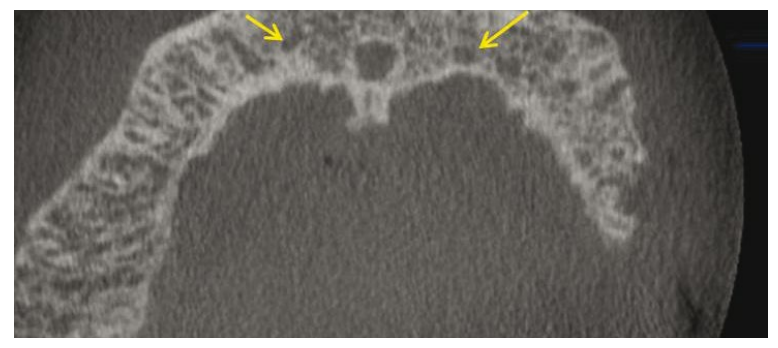

Figure 2. Axial view of cone beam computed tomography shows the accessory canals which were located near palatal cortex, adjacent to nasopalatine canal (arrows).

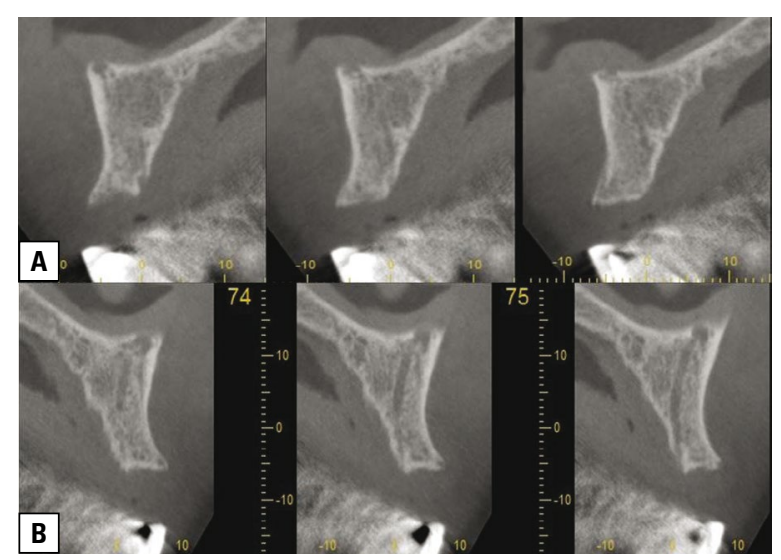

Figure 3. Sagittal cone beam computed tomography slices showing the presence of the canalis sinuosus on the right $(\mathbf{A})$ and left $(\mathbf{B})$ sides.

Rock, TX, USA) at a screen resolution of $1920 \times 1200$ pixels and 32-bit colour depth.

\section{Statistical analysis}

Data were analysed by descriptive statistics. Shapiro-Wilk test was used to test the normality of continuous variables. While all continuous variables were skewed, descriptive statistics were shown as median and interquartile range (IQR). The frequency

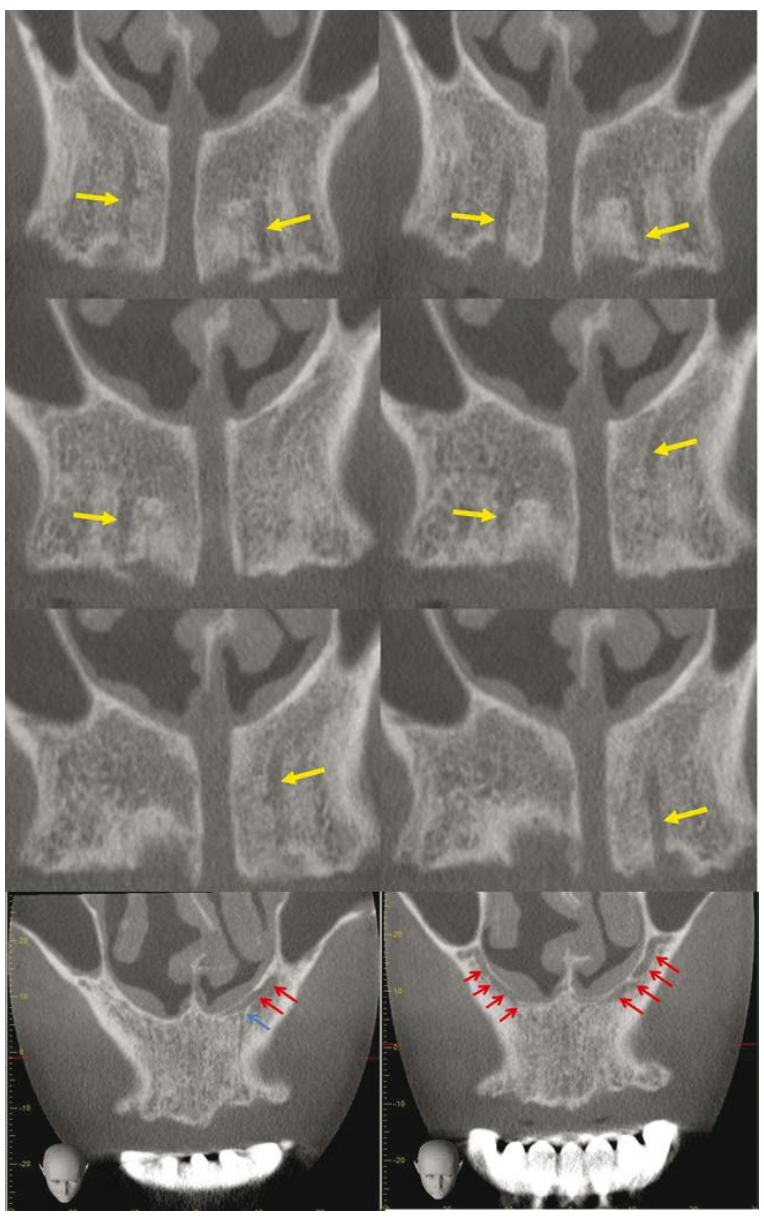

Figure 4. Coronal cone beam computed tomography slices showing the presence and course of the accessory canals (yellow arrows), canalis sinuosus (red arrows) and bifurcation point of canalis sinuosus and accessory canal (blue arrow).

of location of CS was calculated. The Pearson's $\chi^{2}$ test was used to compare categorical variables. Statistical analyses were performed using the IBM SPSS Statistics 22.0 software (IBM Corp. Released 2013. IBM SPSS Statistics for Windows, Version 22.0. Armonk, NY: IBM Corp.) and MS-Excel 2007. The $p$ value $<0.05$ was considered statistically significant.

\section{RESULTS}

A total of $1460 \mathrm{CBCT}$ images were screened. Of these, $672(46.0 \%)$ were from female patients, and $788(54.0 \%)$ were from male patients. 1034 (70.8\%) of 1460 images had at least one AC of CS. The frequency of $A C$ was found higher in females $(72.2 \%$, $485 / 672)$ than in males $(69.7 \%, 549 / 788)$. The median age of female patients was 45.5 (IQR 29.0) years and within the age range of 9 to 84 years. The median age of male patients was 43.0 (IQR 30.0) years and within 
Table 1. Distribution of patients with canalis sinuosus according to age groups and gender

\begin{tabular}{lcccc}
\hline Age groups [years] & $\begin{array}{c}\text { Male } \\
\mathbf{N}(\%)\end{array}$ & $\begin{array}{c}\text { Female } \\
\mathbf{N}(\%)\end{array}$ & $\begin{array}{c}\text { Total } \\
\mathbf{N}(\%)\end{array}$ & $\begin{array}{c}\text { Number of AC } \\
\mathbf{N}(\%)\end{array}$ \\
\hline$<10$ & $6(0.8)$ & $1(0.1)$ & $7(0.5)$ & $13(0.2)$ \\
$10-19$ & $78(9.9)$ & $91(13.5)$ & $169(11.6)$ & $744(11.2)$ \\
$20-29$ & $163(20.7)$ & $78(11.6)$ & $241(16.5)$ & $740(11.1)$ \\
$30-39$ & $102(12.9)$ & $99(14.7)$ & $201(13.8)$ & $1020(15.3)$ \\
$40-49$ & $149(18.9)$ & $125(18.6)$ & $274(18.8)$ & $1350(20.2)$ \\
$50-59$ & $142(18.0)$ & $153(22.8)$ & $295(20.2)$ & $1571(23.6)$ \\
$60-69$ & $101(12.8)$ & $98(14.6)$ & $199(13.6)$ & $889(13.3)$ \\
$\geq 70$ & $47(6.0)$ & $27(4.0)$ & $74(5.1)$ & $341(5.1)$ \\
Total & $788(100.0)$ & $672(100.0)$ & $1460(100.0)$ & $6668(100.0)$ \\
\hline
\end{tabular}

$\mathrm{AC}$ - accessory canal

the age range of 5 to 83 years also. The distribution of gender and age groups of the sample is shown in Table 1. Most frequently referred patient age groups were the $50-59$ age group (20.2\%) followed by $40-49$ age group (18.8\%). The least frequent age groups were $1-10(0.5 \%)$ and over 70 years $(5.1 \%)$.

A total of 6668 ACs were found. The distribution of age groups and number of ACs is shown in Table 1. 1571 (23.6\%) of 6668 ACs were found at the 50-59 age group. The highest frequency of $A C$ is seen at the age group of 50-59. The number of canals and classified localisations were shown in Table 2. According to the table, it can be clearly seen that the lowest number of ACs in anterior maxilla were found in between the region of tooth 23 and tooth 24 ( $n=68,4.6 \%$ ) as well as the region in between tooth 13 and tooth 14 ( $n=88,6.0 \%$ ). Maxillary intercentral region is the area where the ACs were seen most frequently ( $n=653$, $44.7 \%$ ). In addition, it was also found some AC openings around the incisive foramen. Distribution of ACs around incisive foramen is also presented in Table 2. The most common AC openings were seen posterior to the incisive foramen ( $n=128,8.8 \%$ ).

If available, impacted canine teeth were also noted. A total of 158 canine impaction were found. Of these, 58 (36.7\%) were located on the right, 51 (32.3\%) were located on the left. In addition, 49 (31.0\%) bilaterally canine impaction were found. Possible connection between the distribution of canine impaction and AC was also evaluated. However, no significant difference was found according to impacted teeth and presence of CS $\left(\chi^{2}=1.847 ; p=0.174 ;\right.$ Table 3$)$.

\section{DISCUSSION}

The infraorbital nerve is a branch of the maxillary nerve. This nerve is also divided into three alveolar proximal branches; anterior, middle and posterior superior alveolar nerves $[5,13]$. The infraorbital canal gives a small branch on its lateral face close to its midpoint to allow passage of the anterior superior nerve. This small canal, which is generally referred as CS, contains the anterior superior alveolar nerve, as well as veins and arteries [13, 19].

Canalis sinuosus is an anatomical variation which is not well known by clinicians. Only a few case reports and studies were published since first described by Jones in 1939. According to PubMed database, "canalis sinuosus" term reveals only 13 results and gained its popularity in the last 5 years. The widespread acceptance of dental implant procedures and improvement of 3D imaging modalities provide this anatomical variation to gain the importance it deserves.

Several surgical procedures are performed on the anterior portion of maxilla. Increasing the knowledge of exact anatomy will provide success to clinicians. Practitioners should be careful with regard to some important structures such as floor of nasal fossa, nasopalatine canal and incisive foramen. Surgery procedures in the anterior maxilla are also challenging due to biomechanics, phonetic and aesthetic requirements [13]. Although it is a rare situation, the possibility to expose some variations, such as CS or neurovascular bundles, should be taken into account. Hence, before performing a surgical procedure, it is extremely important to consider and exactly locate the presence of anatomical variations [7, 17]. In addition, it was also suggested that replacing an implant contacted with the neurovascular bundle would led to non-integration [15].

Traditional diagnostic imaging techniques such as panoramic and periapical radiography provide two- 
Table 2. Location and distrubition of number of accessory canals in the anterior maxilla

\begin{tabular}{|c|c|c|c|c|c|c|c|c|c|c|c|c|}
\hline \multirow[t]{3}{*}{ Location } & \multicolumn{12}{|c|}{ Number of canals } \\
\hline & \multicolumn{2}{|c|}{0} & \multicolumn{2}{|c|}{1} & \multicolumn{2}{|c|}{2} & \multicolumn{2}{|c|}{3} & \multicolumn{2}{|c|}{4} & \multicolumn{2}{|c|}{5} \\
\hline & $\begin{array}{c}\text { Female } \\
\text { N (\%) }\end{array}$ & $\begin{array}{l}\text { Male } \\
\text { N (\%) }\end{array}$ & $\begin{array}{c}\text { Female } \\
\mathbf{N}(\%)\end{array}$ & $\begin{array}{l}\text { Male } \\
\text { N (\%) }\end{array}$ & $\begin{array}{c}\text { Female } \\
\text { N (\%) }\end{array}$ & $\begin{array}{l}\text { Male } \\
\text { N (\%) }\end{array}$ & $\begin{array}{c}\text { Female } \\
\text { N (\%) }\end{array}$ & $\begin{array}{l}\text { Male } \\
\text { N (\%) }\end{array}$ & $\begin{array}{l}\text { Female } \\
\text { N (\%) }\end{array}$ & $\begin{array}{l}\text { Male } \\
\text { N (\%) }\end{array}$ & $\begin{array}{c}\text { Female } \\
\mathbf{N}(\%)\end{array}$ & $\begin{array}{l}\text { Male } \\
\text { N (\%) }\end{array}$ \\
\hline 11 & $379(56.4)$ & $491(62.3)$ & $284(42.3)$ & $281(35.7)$ & $9(1.3)$ & $14(1.8)$ & $0(0.0)$ & $1(0.1)$ & $0(0.0)$ & $1(0.1)$ & $0(0.0)$ & $0(0.0)$ \\
\hline $11-12$ & $575(85.6)$ & $729(92.5)$ & $95(14.1)$ & $59(7.5)$ & $2(0.3)$ & $0(0.0)$ & $0(0.0)$ & $0(0.0)$ & $0(0.0)$ & $0(0.0)$ & $0(0.0)$ & $0(0.0)$ \\
\hline 12 & $402(59.8)$ & $472(59.9)$ & $261(38.8)$ & $308(39.1)$ & $8(1.2)$ & $8(1.0)$ & $1(0.1)$ & $0(0.0)$ & $0(0.0)$ & $0(0.0)$ & $0(0.0)$ & $0(0.0)$ \\
\hline $12-13$ & $599(89.1)$ & $733(93.0)$ & $73(10.9)$ & $54(6.9)$ & $0(0.0)$ & $1(0.1)$ & $0(0.0)$ & $0(0.0)$ & $0(0.0)$ & $0(0.0)$ & $0(0.0)$ & $0(0.0)$ \\
\hline 13 & $405(60.3)$ & $506(64.2)$ & $263(39.1)$ & $275(34.9)$ & $4(0.6)$ & $6(0.8)$ & $0(0.0)$ & $1(0.1)$ & $0(0.0)$ & $0(0.0)$ & $0(0.0)$ & $0(0.0)$ \\
\hline $13-14$ & $625(93.0)$ & $747(94.8)$ & $47(7.0)$ & $41(5.2)$ & $0(0.0)$ & $0(0.0)$ & $0(0.0)$ & $0(0.0)$ & $0(0.0)$ & $0(0.0)$ & $0(0.0)$ & $0(0.0)$ \\
\hline 14 & $471(70.1)$ & $589(74.7)$ & $198(29.5)$ & $197(25.0)$ & $3(0.4)$ & $2(0.3)$ & $0(0.0)$ & $0(0.0)$ & $0(0.0)$ & $0(0.0)$ & $0(0.0)$ & $0(0.0)$ \\
\hline $11-21$ & $340(50.6)$ & $467(59.3)$ & $76(11.3)$ & $81(10.3)$ & $252(37.5)$ & $231(29.3)$ & $4(0.6)$ & $8(1.0)$ & $0(0.0)$ & $1(0.1)$ & $0(0.0)$ & $0(0.0)$ \\
\hline 21 & $360(53.6)$ & $467(59.3)$ & $299(44.5)$ & $300(38.1)$ & $10(1.5)$ & $19(2.4)$ & $2(0.3)$ & $1(0.1)$ & $0(0.0)$ & $1(0.1)$ & $1(0.1)$ & $0(0.0)$ \\
\hline $21-22$ & $569(84.7)$ & $730(92.6)$ & $100(14.9)$ & $58(7.4)$ & $3(0.4)$ & $0(0.0)$ & $0(0.0)$ & $0(0.0)$ & $0(0.0)$ & $0(0.0)$ & $0(0.0)$ & $0(0.0)$ \\
\hline 22 & $369(54.9)$ & $463(58.8)$ & $290(43.2)$ & 305 (38.7) & $12(1.8)$ & $20(2.5)$ & $1(0.1)$ & $0(0.0)$ & $0(0.0)$ & $0(0.0)$ & $0(0.0)$ & $0(0.0)$ \\
\hline $22-23$ & $604(89.9)$ & 715 (90.7) & $68(10.1)$ & $71(9.0)$ & $0(0.0)$ & $2(0.3)$ & $0(0.0)$ & $0(0.0)$ & $0(0.0)$ & $0(0.0)$ & $0(0.0)$ & $0(0.0)$ \\
\hline 23 & $368(54.8)$ & $488(61.9)$ & $296(44.0)$ & $287(36.4)$ & $8(1.2)$ & $13(1.6)$ & $0(0.0)$ & $0(0.0)$ & $0(0.0)$ & $0(0.0)$ & $0(0.0)$ & $0(0.0)$ \\
\hline $23-24$ & $634(94.3)$ & $758(96.2)$ & 37 (5.5) & $30(3.8)$ & $1(0.1)$ & $0(0.0)$ & $0(0.0)$ & $0(0.0)$ & $0(0.0)$ & $0(0.0)$ & $0(0.0)$ & $0(0.0)$ \\
\hline 24 & $455(67.7)$ & $590(74.9)$ & $216(32.1)$ & $196(24.9)$ & $1(0.1)$ & $2(0.3)$ & $0(0.0)$ & $0(0.0)$ & $0(0.0)$ & $0(0.0)$ & $0(0.0)$ & $0(0.0)$ \\
\hline Anterior of IF & $618(92.0)$ & $714(90.6)$ & $50(7.4)$ & $71(9.0)$ & $4(0.6)$ & $3(0.4)$ & $0(0.0)$ & $0(0.0)$ & $0(0.0)$ & $0(0.0)$ & $0(0.0)$ & $0(0.0)$ \\
\hline Posterior of IF & $661(98.4)$ & 770 (97.7) & $11(1.6)$ & $18(2.3)$ & $0(0.0)$ & $0(0.0)$ & $0(0.0)$ & $0(0.0)$ & $0(0.0)$ & $0(0.0)$ & $0(0.0)$ & $0(0.0)$ \\
\hline $\begin{array}{l}\text { Lateral to IF } \\
\text { (right) }\end{array}$ & $666(99.1)$ & 787 (99.5) & $680.9)$ & $4(0.5)$ & $0(0.0)$ & $0(0.0)$ & $0(0.0)$ & $0(0.0)$ & $0(0.0)$ & $0(0.0)$ & $0(0.0)$ & $0(0.0)$ \\
\hline $\begin{array}{l}\text { Lateral to IF } \\
\text { (left) }\end{array}$ & $668(99.4)$ & 781 (99.1) & $4(0.6)$ & $7(0.9)$ & $0(0.0)$ & $0(0.0)$ & $0(0.0)$ & $0(0.0)$ & $0(0.0)$ & $0(0.0)$ & $0(0.0)$ & $0(0.0)$ \\
\hline
\end{tabular}

IF - incisive foramen

Table 3. Location of impacted canine tooth and presence of canalis sinuosus according to gender

\begin{tabular}{lccc}
\hline $\begin{array}{l}\text { Location of impacted } \\
\text { canine tooth }\end{array}$ & $\begin{array}{c}\text { Male } \\
\mathbf{N}(\%)\end{array}$ & $\begin{array}{c}\text { Female } \\
\mathbf{N}(\%)\end{array}$ & $\begin{array}{c}\text { Total } \\
\mathbf{N}(\%)\end{array}$ \\
\hline Right & $23(35.4)$ & $35(37.6)$ & $58(36.7)$ \\
Left & $19(29.2)$ & $32(34.4)$ & $51(32.3)$ \\
Bilateral & $23(35.4)$ & $26(28.0)$ & $49(31.0)$ \\
Total & $65(100.0)$ & $93(100.0)$ & $158(100.0)$ \\
\hline
\end{tabular}

dimensional (2D) images. Due to their limitations this canal is hardly recognised. Moreover, many practitioners identify this structure as a periapical radiolucency or pathologic lesion [3, 17]. The widespread use of CBCT in dentistry allowed obtaining detailed and accurate 3D views of the structures, high resolution images with greater reliability and reproducibility than 2D images [13, 14, 17]. Especially, due to increased frequency of dental implant applications, preoperative multiplanar radiologic evaluation became necessary to avoid unexpected complications.

Although some reports in literature emphasize that the CS was rare [13, 14], Wanzeler et al. [17] reported the frequency of this structure as $87.5 \%$ in 100 CBCT scans. They also suggested that anatomical structure should not be considered as an anatomical variation. However, it should be noticed that among the studies found in PubMed, their study sample was the smallest. The study which assessed 1000 CBCT scans by Machado et al. [8] is one of the study with the largest sample size. They found the frequency of $52.1 \%$. Evaluation of 500 CBCT scans by Manhaes Junior et al. [9] is another largest sample size. According to their report, frequency of CS was 36.2\%. Among the articles published in PubMed, de Oliveira Santos et al. [2] reported the lowest frequency of $15.7 \%$ in 178 CBCT scans. This study has found ACs in $70.8 \%$ of $1460 \mathrm{CBCT}$ scans. To the best of our knowledge this is the study with the largest sample size among the studies published so far. And also revealed second highest frequency rate in literature after Wanzeler et al. [17]. It could be several possible explanations for 
these different frequencies. One of the possible reasons for differences could be using different methods. Von Arx et al. [16] reported the frequency of $27.8 \%$ only when an AC diameter was at least $1 \mathrm{~mm}$. They also reported the frequency was $55.1 \%$, when they considered all ACs, even smaller than $1 \mathrm{~mm}$.

According to literature, although there was a slight tendency to seeing more ACs in males than in females $[8,16,18]$ but no statistically significant differences in presence of $A C$ between genders was revealed. Although de Oliveira Santos et al. [2] reported that they found 15 females against 13 males with accessory bony canal but they also mentioned that they did not reveal any statistical differences. Although, in this study, it was found a slight tendency to higher prevalence in females similarly as in de Oliveira Santos et al.'s [2] study, but the results of this article are in agreement with those previous studies in which between-gender differences were not statistically significant $\left(\chi^{2}=1.099 ; p=0.294\right)$.

With regard to age, there was a slight tendency towards seeing more ACs in older age groups when compared with younger people. The presence of ACs which derived from the CS was not found to be correlated with sex and age groups. Present study revealed similar results and in agreement with other studies available in literature $[2,8,16]$.

The regions where ACs are mostly seen vary in literature. von Arx et al. [16] reported that the most commonly found region was palatal to central incisors. Manhaes Junior et al. [9] reported that it was "beside the incisive foramen" and de Oliveira Santos et al. [2] found it "near the incisors or canine". Machado et al. [8] defined the most commonly seen location as "palatal to the anterior maxillary teeth". According to our results, the ACs deriving from the CS were mostly found in maxillary intercentral region. Although the term "palatal to the anterior maxillary teeth" was a comprehensive definition of the most commonly seen area for $\mathrm{AC}$, this article also reaffirms.

\section{CONCLUSIONS}

In conclusion, although CS is described by some authors as "a rare anatomical variation", it is concluded that it is a common anatomical structure. Due to the fact that it contains anterior superior alveolar nerve as well as veins and arteries, exact localisation of this structure will allow surgeons to avoid nerve damage, unexpected bleeding, haemorrhage and complications. In addition to these complications, replacing an implant contacted with the neurovascular bundle will lead to non-integration. Accurate diagnosis should be made by using several radiologic techniques; however, CS is not often seen in conventional radiographs because of their limitations. 3D imaging modalities could be an appropriate option for the comprehensive evaluation and accurate diagnosis.

\section{Acknowledgements}

This study was presented as a poster presentation in $15^{\text {th }}$ European Congress of Dentomaxillofacial Radiology, Cardiff, Wales.

\section{REFERENCES}

1. Allareddy V, Vincent SD, Hellstein JW, et al. Incidental findings on cone beam computed tomography images. Int J Dent. 2012; 2012: 871532, doi: 10.1155/2012/871532, indexed in Pubmed: 23304148.

2. de Oliveira-Santos C, Rubira-Bullen IRF, Monteiro SAC, et al. Neurovascular anatomical variations in the anterior palate observed on $\mathrm{CBCT}$ images. Clin Oral Implants Res. 2013; 24(9): 1044-1048, doi: 10.1111/j.16000501.2012.02497.x, indexed in Pubmed: 22587228.

3. Elnaz Moslehifard. Computer Aided Techniques Developed for Diagnosis and Treatment Planning in Implantology, Implant Dentistry - The Most Promising Discipline of Dentistry 2011, Prof. Ilser Turkyilmaz (Ed.), ISBN:978953-307-481-8.

4. Greenstein G, Tarnow D. The mental foramen and nerve: clinical and anatomical factors related to dental implant placement: a literature review. J Periodontol. 2006; 77(12): 1933-1943, doi: 10.1902/jop.2006.060197, indexed in Pubmed: 17209776.

5. Hu KS, Kwak HH, Song WC, et al. Branching patterns of the infraorbital nerve and topography within the infraorbital space. J Craniofac Surg. 2006; 17(6): 1111-1115, doi: 10.1097/01. scs.0000236436.97720.5f, indexed in Pubmed: 17119413.

6. Imada TS, Fernandes LM, Centurion BS, et al. Accessory mental foramina: prevalence, position and diameter assessed by cone-beam computed tomography and digital panoramic radiographs. Clin Oral Implants Res. 2014; 25(2): e94-e99, doi: 10.1111/clr.12066, indexed in Pubmed: 23167944.

7. Liang $\mathrm{X}$, Jacobs $\mathrm{R}$, Martens $\mathrm{W}$, et al. Macro- and microanatomical, histological and computed tomography scan characterization of the nasopalatine canal. J Clin Periodontol. 2009; 36(7): 598-603, doi: 10.1111/j.1600051X.2009.01429.x, indexed in Pubmed: 19538333.

8. Machado VC, Chrcanovic BR, Felippe MB, et al. Assessment of accessory canals of the canalis sinuosus: a study of 1000 cone beam computed tomography examinations. Int J Oral Maxillofac Surg. 2016; 45(12): 1586-1591, doi: 10.1016/j. ijom.2016.09.007, indexed in Pubmed: 27720336.

9. Manhães Júnior LR, Villaça-Carvalho MF, Moraes ME, et al. Location and classification of Canalis sinuosus for cone beam computed tomography: avoiding misdiagnosis. Braz Oral Res. 2016; 30(1): e49, doi: 10.1590/1807-3107BOR2016.vol30.0049, indexed in Pubmed: 27119586. 
10. Mraiwa N, Jacobs $R$, Moerman $P$, et al. Presence and course of the incisive canal in the human mandibular interforaminal region: two-dimensional imaging versus anatomical observations. Surg Radiol Anat. 2003; 25(5-6): 416-423, doi: 10.1007/s00276-003-0152-8, indexed in Pubmed: 13680184.

11. Neves FS, Crusoé-Souza M, Franco LC, et al. Canalis sinuosus: a rare anatomical variation. Surg Radiol Anat. 2012; 34(6): 563-566, doi: 10.1007/s00276-011-0907-6, indexed in Pubmed: 22134775.

12. Price JB, Thaw KL, Tyndall DA, et al. Incidental findings from cone beam computed tomography of the maxillofacial region: a descriptive retrospective study. Clin Oral Implants Res. 2012; 23(11): 1261-1268, doi: 10.1111/j.16000501.2011.02299.x, indexed in Pubmed: 22092929.

13. Shelley AM, Rushton VE, Horner K. Canalis sinuosus mimicking a periapical inflammatory lesion. Br Dent J. 1999; 186(8): 378-379, indexed in Pubmed: 10365458.

14. Torres MG, de Faro Valverde L, Vidal MT, et al. Branch of the canalis sinuosus: a rare anatomical variation: a case report.
Surg Radiol Anat. 2015; 37(7): 879-881, doi: 10.1007/ s00276-015-1432-9, indexed in Pubmed: 25616849.

15. von Arx T, Lozanoff $S$. Anterior superior alveolar nerve (ASAN). Swiss Dent J. 2015; 125(11): 1202-1209, indexed in Pubmed: 26631255.

16. von Arx T, Lozanoff $S$, Sendi $P$, et al. Assessment of bone channels other than the nasopalatine canal in the anterior maxilla using limited cone beam computed tomography. Surg Radiol Anat. 2013; 35(9): 783-790, doi: 10.1007/ s00276-013-1110-8, indexed in Pubmed: 23539212.

17. Wanzeler AM, Marinho CG, Alves Junior SM, et al. Anatomical study of the canalis sinuosus in 100 cone beam computed tomography examinations. Oral Maxillofac Surg. 2015; 19(1): 49-53, doi: 10.1007/s10006-014-0450-9, indexed in Pubmed: 24752931.

18. Warhekar S, Nagarajappa S, Dasar PL, et al. Incidental findings on cone beam computed tomography and reasons for referral by dental practitioners in indore city (m.p). J Clin Diagn Res. 2015; 9(2): ZC21-ZC24, doi: 10.7860/ JCDR/2015/11705.5555, indexed in Pubmed: 25859519.

19. Warwick R, Williams PL. Williams PL. Grays anatomy. 35th ed. Longman. Edinburg, 1973. 